\title{
Products of the interaction of copper and benzenediazonium tetrafluoroborate in acetonitrile medium
}

\author{
Eugen P. KOVAL'CHUK ${ }^{1 *}$, Oleksandr V. RESHETNYAK ${ }^{1}$, Vasyl' Ya. SMETANETS'KYJ ${ }^{1}$, \\ Jerzy BŁAŻEJOWSKI ${ }^{2}$ \\ ${ }^{1}$ Department of Physical and Colloid Chemistry, Faculty of Chemistry, Ivan Franko National University of Lviv, \\ Kyryla i Mefodiya St. 6, 79005 Lviv, Ukraine \\ ${ }^{2}$ Department of Physical Chemistry, Faculty of Chemistry, University of Gdańsk, \\ Sobieskiego St. 18, 80-952 Gdańsk, Poland \\ * Corresponding author.Tel.: +380-32-2600397; e-mail: kovalch@franko.lviv.ua
}

Received July 2, 2009; accepted December 23, 2009; available on-line April 27, 2010

The products of the chemical interaction of copper and a concentrated $(\geq 0.05 \mathrm{M})$ benzenediazonium tetrafluoroborate (BDFB) solution in acetonitrile have been studied. It is proposed on the base of the obtained results that the intermediate of the copper dissolution-ionization, which corresponds to an absorption band with a maximum at $432 \mathrm{~nm}$, is the mixed complex $\left[\mathrm{Cu}\left(\mathrm{N} \equiv \mathrm{N}-\mathrm{C}_{6} \mathrm{H}_{5}\right)\left(\mathrm{N} \equiv \mathrm{C}-\mathrm{CH}_{3}\right)_{3}\right]^{+}$, which contains three acetonitrile molecules and the copper ion covalently bonded to an azophenyl radical. This complex is thermodynamically unstable and decomposes slowly into a colorless crystalline and a black amorphous phase. The crystalline phase was identified as $\left[\mathrm{Cu}\left(\mathrm{N} \equiv \mathrm{C}-\mathrm{CH}_{3}\right)_{4}\right]^{+} \mathrm{BF}_{4}^{-}$by $\mathrm{X}$-ray diffraction, while the amorphous phase is a mixture of oligomeric products of different lengths, which are formed as the result of the condensation of azophenyl and phenyl radicals.

Copper / Benzenediazonium tetrafluoroborate / Acetonitrile / Dissolution-ionization / Cu(I) complexes / Crystal structure

Introduction

During the last 10 years, the salts of arenediazonium (DAS) have been used to modify carbon materials, metal, indium-tin oxide (ITO) and semiconductor ( $\mathrm{Si}$, GaAs) surfaces [1]. Such materials, functionalized by organic mono- or multilayers, are widely applied in the development of chemically modified stationary phases for electrochemically modulated liquid chromatography [2]. The modification of a diamond surface by reduction of DAS is used in the design of a universal composition platform for the immobilization of chemical and biological components [3] and for
Suzuki reactions in the surface layer [4]. In addition, DAS can be the initial materials for the design of spatially assembled molecular structures, which makes it possible to study the phenomena that are the basis of molecular and optical electronics [5,6].

Various methods can be used to generate reactive intermediates from diazonium salts, for example electrochemical reduction, thermolysis, photolysis, radiolysis, or chemical reduction. Reduction of the aryldiazonium cation (DAC) involves the generation of a reactive diazonium radical, or the cleavage of nitrogen and formation of a phenyl radical, according to the equations [7]:

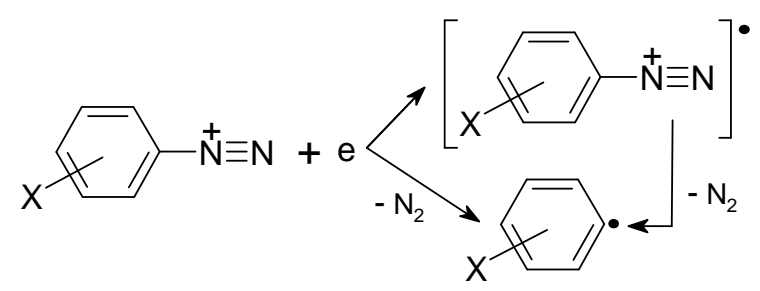


The free radical particles produced in this way can react with the solvent, other phenyl radicals and the electrode material. The interaction of the phenyl and azophenyl radicals with the initial aryldiazonium cations, as well as their direct and crossrecombination, lead to the formation of biphenyl, oligomeric and polymeric adducts [8,9], while the electrochemical reduction of $p$-tolyldiazonium tetrafluoroborate on a stationary mercury electrode is accompanied by the formation of $p$-ditolylmercury [10]. Ahlberg et al. observed the blocking of $\mathrm{Hg}, \mathrm{Pt}$ and $\mathrm{Au}$ electrodes by the formation of hydrophobic films during the electrochemical reduction of 1-naphthalenediazonium tetrafluoroborate in acetonitrile [11]. The strategy of the electrochemical reduction of a wide variety of aromatic diazonium salts can be used for the modification of the surfaces of iron [12] and carbon materials [13-16]. Moreover, Belanger et al. have described the in situ modification of carbon soot and copper electrodes during the synthesis of the corresponding diazonium salts without their isolation $[17,18]$.

The diazo-group bonded to the benzene ring $[\mathrm{ArN} \equiv \mathrm{N}]^{+}$is a unique formation with a specific distribution of electron density, that determines the high reactivity of DAS in different chemical reactions. Because of the strong oxidative potential the aryldiazonium cations also react directly (without any electrochemical induction) with both metallic and carbon surfaces, which leads to the formation of $\mathrm{C}-\mathrm{Me}$ or $\mathrm{C}-\mathrm{C}$ (substrate) covalent bonds [2,19-23]. However, the intensive dissolution-ionization of $\mathrm{Cu}$ [24-26], Mg [25], Al, $\mathrm{Zn}$ and $\mathrm{Ni}$ [27] proceeds simultaneously with the modification of the surfaces in concentrated $(\geq 0.05 \mathrm{M})$ DAS aprotic solutions. On account of the specific properties of copper, which catalyzes aggregate reactions with DAS participation $[7,28,29]$, we studied the products of the chemical interaction of benzenediazonium tetrafluoroborate (BDFB) with copper in details, which gave us the possibility to propose a mechanism for this process.

\section{Experimental}

Freshly distillated aniline (Linegal Chemicals, analytical grade) was used for the synthesis of benzenediazonium tetrafluoroborate (BDFB). The diazoniation of aniline and purification of the product were carried out following well-known procedures [30]. Only freshly prepared benzenediazonium tetrafluoroborate was used in all the experiments. Acetonitrile (ACN) (Merck KgaA, LiChrosolv ${ }^{\circledR}$, $\geq 99.8 \%$, isocratic grade for liquid chromatography, content of water $\leq 0.05 \%$ ) was used without further purification. The purity of copper (foil with thickness $0.5 \mathrm{~mm}$ (Sigma-Aldrich) and high-dispersed powder) was 99.98 wt.\%.

All the experiments were carried out at room $\left(20^{\circ} \mathrm{C}\right)$ temperature.
Infrared spectra were recorded on a BRUKER IFS 66 spectrophotometer over the $5000-400 \mathrm{~cm}^{-1}$ range. All spectra were collected with an accumulation of 32 scans.

The structure of single crystals isolated from the final reaction mixture of the interaction of copper and BDFB in an acetonitrile solution, was preliminarily studied by photographic methods. Diffraction data was then recorded on a single crystal diffractometer DARCh-1 (Mo $K \alpha$-radiation, Zn $\beta$-filter, $\theta / 2 \theta$ scan) and used to determine the structure. The intensities were corrected for the Lorentz factor and polarization. The structure was solved by direct methods; the light atoms were localized from Fourier difference syntheses, and the positions of the hydrogen atoms were determined from geometrical considerations. The CSD program package [31] was used for the computations.

\section{Results and discussion}

Reduction of diazonium salts on carbon, semiconductor or metal surfaces proceeds through a preliminary stage of chemosorption that leads to the formation of a covalently grafted mono- or multilayer on the substrate surface. The interaction energy of the adsorption complex depends on the type and the state of the electrode surface, on the nature and position of the substituent group in the phenyl ring of the diazonium salt, the solvent type and temperature. If the $\mathrm{C}-\mathrm{Me}$ bond energy and the metal lattice energy are comparable, direct electron transfer from the electrode to the particles of the adsorbate is possible. This leads to ionization/dissolution of the metal. In a different way, electron transfer takes place only when a potential is applied from an external source. The adsorbents can be divided into two groups from this point of view [24]. The first group consists of "inactive" materials, such as $\mathrm{Pt}, \mathrm{Au}, \mathrm{Ag}, \mathrm{Pd}, \mathrm{V}$, or glassy carbon, while the following "active" materials: $\mathrm{Cu}, \mathrm{Al}, \mathrm{Zn}, \mathrm{Fe}, \mathrm{Mg}$, In, Ga, alkali and alkaline-earth elements belong to the second group. The electrochemical polarization of inactive and active metals is different.

The phenomenon of ionization-dissolution of metals in aprotic DAS solutions is determined by the strong oxidative properties of DAC. The rate of this heterogeneous reduction of DAC depends on the contact area of the metallic phase and the BDFB solution. Therefore the replacement of the metal sheet by fine-dispersed metal powder leads to a sharp increase of the reaction rate. Complete dissolution of the $\mathrm{Cu}$ sheet was observed after 8-10 hours, whereas the same reaction using an equivalent quantity of $\mathrm{Cu}$ powder was completed after 10 minutes. The reaction of BDFB with copper is accompanied by an intense gas evolution, which begins immediately after the addition of the DAS solution to the copper powder. Then this process slows down as the result of the 
exhaustion of the DAS solution. In the case when copper powder was used, the part of metal that had reacted with DAS was only $70 \%$ using a stoichiometric excess of DAS solution (the initial molar ratio $\mathrm{Cu}$ : DAS was equal to $0.7: 1$ ), although no DAS was detected in the final solution. Moreover, according to the volume of evolved nitrogen the amount of DAS that had reacted with copper was $68.7 \%$. Consequently it was assumed that only $\sim 70 \%$ of the initial BDFB had dediazotized during the reduction by metallic copper:

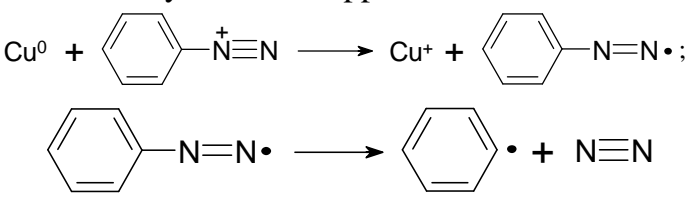

These radicals can react with each other, with a metallic surface, the solvent or initial DAS. The products of the direct or cross-recombination of the phenyl and azophenyl radicals are, respectively, biphenyl

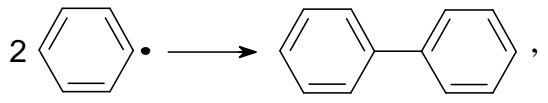

azobenzene,<smiles>[C+](N=Nc1ccccc1)c1ccc(N=Nc2ccccc2)cc1</smiles>

or diazobenzene.<smiles>[C+]1=CC=CC=CC1N=Nc1ccc(N=NN=Nc2ccccc2)cc1</smiles>

Cohen et al. detected dimeric products, exactly biphenyl and azobenzene type, during the reduction of 4-nitrobenzenediazonium tetrafluoroborate by tetrakis(acetonitrile)copper(I) perchlorate $\left(\mathrm{CH}_{3} \mathrm{CN}\right)_{4} \mathrm{Cu}^{+} \mathrm{ClO}_{4}^{-}$in acetonitrile [32]. The formation of azobenzene and diazobenzene explains the experimental observation that $\sim 30 \%$ of the initial DAS does not take part in the dediazotization reaction. The highly reactive phenyl radicals can eliminate hydrogen from solvent molecules with the formation of benzene. This reaction proceeds slowly in acetonitrile, due to the low mobility of the hydrogen atoms in the methyl group. However, $\mathrm{Ar}-\mathrm{H}$ forms with a $30 \%$ yield when another solvent is used, for example tetrahydrofuran [17]. Another possible reaction is the interaction of phenyl radicals with the initial benzenediazonium cations. For example, the phenyl radicals can eliminate the hydrogen in the para-position of the DAS cation.

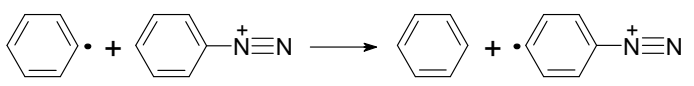

Moreover, these reactions can lead to the formation of oligomeric or polymeric products [8].

The interaction of DAS with $\mathrm{Cu}(\mathrm{I})$ cations formed in reaction (2) involves the formation of arylcopper according to the equations

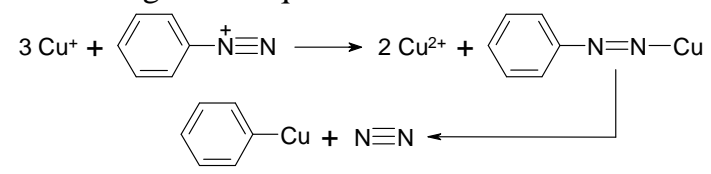

Cohen et al. showed that high concentrations of $\mathrm{Cu}(\mathrm{I})$ ions favor the formation of azobenzene, while for high concentrations of $\mathrm{Cu}(\mathrm{II})$ and phenyldiazo cations, mainly biphenyl is formed [32]. On the other hand, $\mathrm{Cu}(\mathrm{I})$ ions easily form complexes with different ligands. For example, mononuclear complexes of $\mathrm{Cu}(\mathrm{I})$ with acetylene [33], propargyl alcohol [34], 4,5-dimethyl-2-phenylphospharin [35], styrene [36] and binuclear complexes with 1,2,4-triphospholil [37], and azophenine [38] have been reported and their crystal structures determined. Therefore the possibility of complexation must be taken into account during reactions of $\mathrm{Cu}(\mathrm{I})$ ions in aprotic solution. The nitrogenated components of the reaction mixture, i.e. the solvent molecules (ACN) and the undenitridated products of the DAS reduction (azo- and diazobenzenes) can be the ligands in such complexes in the studied system. In the system investigated here the initial light-yellow DAS solution rapidly changed color to red after the contact with metallic copper. In our opinion the strong color saturation of the solution indicates complexation in the system. Earlier studies carried out in situ by UV-visible absorption spectroscopy have shown that an absorption band with a maximum at $260 \mathrm{~nm}$ corresponds to the initial BDFB solution in acetonitrile [24]. The intensity of this band decreases with time in the presence of copper, which can easily be explained by the decrease of the concentration of DAS, as the result of its interaction with the copper sheet. In the same time, a new band with a maximum in the $420-432 \mathrm{~nm}$ region arises in the spectrum [24]. It can be attributed to products of the interaction between BDFB and the metal because its intensity increases with time. In our opinion this absorption band corresponds to a complex of copper in low oxidation state, analogous to the complex of $\mathrm{Cu}(\mathrm{I})$ and $o$-phenanthroline [39].

In order to determine the mechanism of copper ionization-dissolution during the oxidation of copper by BDFB, we decided to study in detail the reaction products, namely the organic layer and the amorphous and crystalline phases that formed, respectively, on the surface of the copper sheet and in the volume of the reaction system after partial evaporation of the solvent. The IR spectra of the initial DAS and of the product formed on the surface of the $\mathrm{Cu}$ sheet do not differ significantly, in spite of the visible changes in the reaction system (Fig. 1). The valence vibrations of the diazo-group in the initial DAS correspond to an absorption band with a maximum at $2290 \mathrm{~cm}^{-1}$. The diazo-group transforms during the DAS reduction, either by dediazotization or by the formation of an azo-group, i.e. it is not among the reaction products. However, as seen in Fig. 1 (spectrum 2), a band at $2290 \mathrm{~cm}^{-1}$, though somewhat narrowed, is also present in the spectrum of the undissolved reaction product. This observation can be explained by the fact that a band with a maximum at $2290 \mathrm{~cm}^{-1}$ is not unique, but also nitriles, isocyanates and isocyanides absorb in this spectral region [40]. The band at $1050 \mathrm{~cm}^{-1}$, which 
is analogous to the band in the spectrum of the initial $\mathrm{BDFB}$, confirms the presence of $\mathrm{BF}_{4}{ }^{-}$ions in the reaction products. The band in the region $1610-1660 \mathrm{~cm}^{-1}$ may be attributed to vibrations of the azo-group $\left(v_{\mathrm{N}=\mathrm{N}}\right)$, however the vibrations of $\mathrm{C}=\mathrm{N}$ groups appear in the same region. These facts lead to the conclusion that solvent molecules $(\mathrm{ACN})$ and $\mathrm{BF}_{4}^{-}$ ions may be present in the mixture of the products of the interaction of DAS with copper.

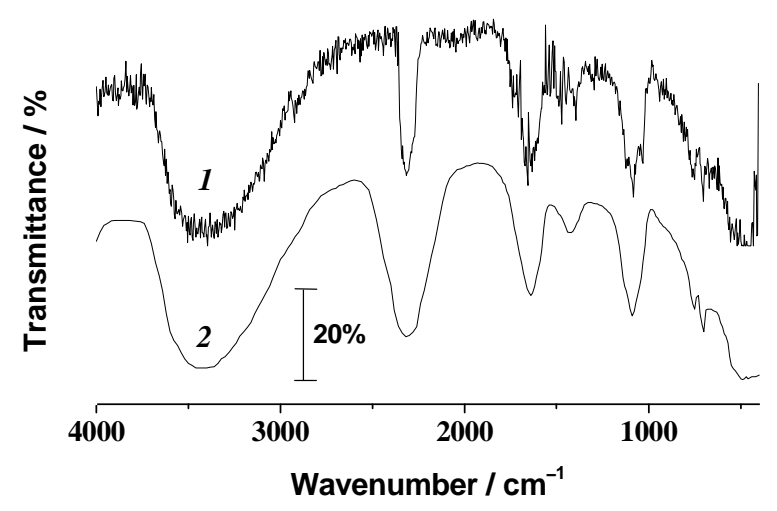

Fig. 1 IR spectra of initial BDFB (1) and the product (2) formed on the surface of a copper sheet after interaction with a BDFB acetonitrile solution.

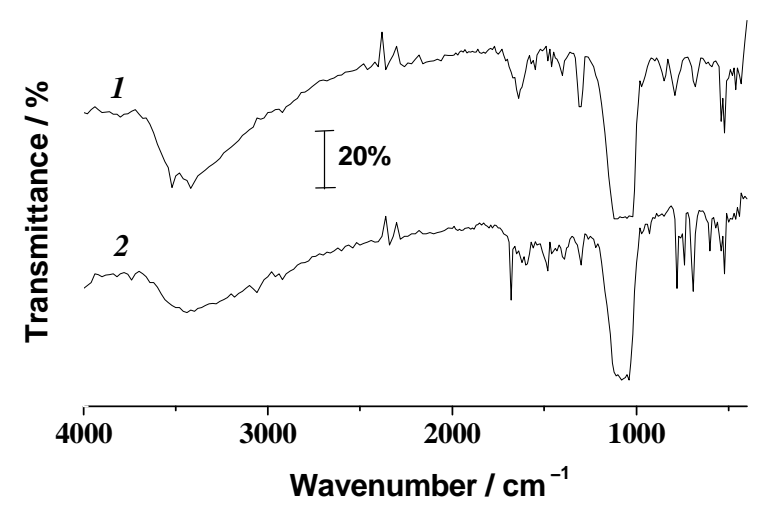

Fig. 2 IR spectra of the crystalline (1) and amorphous (2) phases that were observed after complete evaporation of the solvent from the reaction mixture of $\mathrm{BDFB}$ and copper powder in acetonitrile.

After 24 hours of copper dissolution the reaction mixture was homogeneous. However, light yellow transparent crystals precipitated from the solution and a suspension with a red-brown (black after complete drying) dispersed phase formed during slow spontaneous evaporation of the solvent at room temperature. After complete evaporation of the solvent a mixture of amorphous and crystalline phases had formed in the system. The largest crystals were cleaned from the thin coating of amorphous phase and then studied by IR spectroscopy and X-ray diffraction. The separation of the dispersed phase was not successful because this amorphous phase always contained small crystals of the crystalline phase. Therefore there are few differences between the IR spectra of the crystalline and amorphous phases (Fig. 2). The main difference concerns the position and intensity of the absorption bands in the 680-850 and $1300-1625 \mathrm{~cm}^{-1}$ wave number regions. The absorption band of the amorphous phase at $1600 \mathrm{~cm}^{-1}$ is connected with the vibration mode of the azo-group, while the bands at 1300 and $1390 \mathrm{~cm}^{-1}$ are present in the spectra of both the crystalline and amorphous phases and can be attributed to deformation vibrations $\delta_{\mathrm{C}-\mathrm{N}}$ [41]. Taking into consideration the results of previous studies of products of DAS electrochemical reduction $[8,42]$, it may be argued that the amorphous phase is a mixture of oligomeric nitrogen-containing organic compounds, which form as the result of the condensation of azophenyl radicals and products of their decomposition.

A well-shaped crystal $(5 \times 2 \times 1 \mathrm{~mm})$ was used for $\mathrm{X}$-ray diffraction studies. From the data collected on a single-crystal diffractometer the chemical composition, the crystal lattice (space group) and the atomic parameters were determined (see Table 1). It was found that the structural subunit of the crystal is the already known complex $\mathrm{Cu}\left(\mathrm{NCCH}_{3}\right)_{4} \cdot \mathrm{BF}_{4}$ [43] (Fig. 3) The crystal structure is in good agreement with the IR absorption spectroscopy data (Fig. 2), where acetonitrile and tetrafluoroborate anions were identified.

The formation of a four-coordinated $\mathrm{Cu}(\mathrm{I})$ complex requires some comments. Shih et al. [44,45] concluded, based on studies of the electrochemical dissolution of copper in monoethanolamine, where the complex $\left[\mathrm{Cu}^{\mathrm{II}}(\mathrm{MEA})_{4}\right]^{2+}$ forms (MEA monoethanolamine molecule), that tetrahedral coordination of ligands is typical for $\mathrm{Cu}$ (II) ions. A complex with coordination number two, namely $\left[\mathrm{Cu}^{\mathrm{I}}(\mathrm{MEA})_{2}\right]^{+}$, was found for the ions $\mathrm{Cu}(\mathrm{I})$. Coordination number two was also observed for the complex of $\mathrm{Cu}(\mathrm{I})$ with 2,9-dimethyl-1,10phenanthroline [46]. However, well studied complexes of $\mathrm{Cu}(\mathrm{I})$ with tetrahedral coordination of ligands also exist. For example, the complex $\mathrm{Cu}\left(\mathrm{CH}_{3} \mathrm{CN}\right)_{4} \mathrm{ClO}_{4}$ is formed between $\mathrm{Cu}(\mathrm{I})$ cations and acetonitrile ligands [47].

The complex $\mathrm{Cu}\left(\mathrm{CH}_{3} \mathrm{CN}\right)_{4} \cdot \mathrm{BF}_{4}$ is the final crystalline product of the copper dissolution during oxidation by DAS. In our opinion, the first stage is the formation of a mixed $\mathrm{Cu}(\mathrm{I})$ complex, where azophenyl radicals, in addition to acetonotrile molecules, are in the coordination sphere. Its formation can be represented by the following equations:

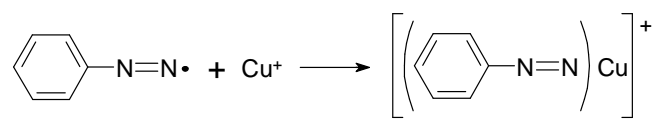



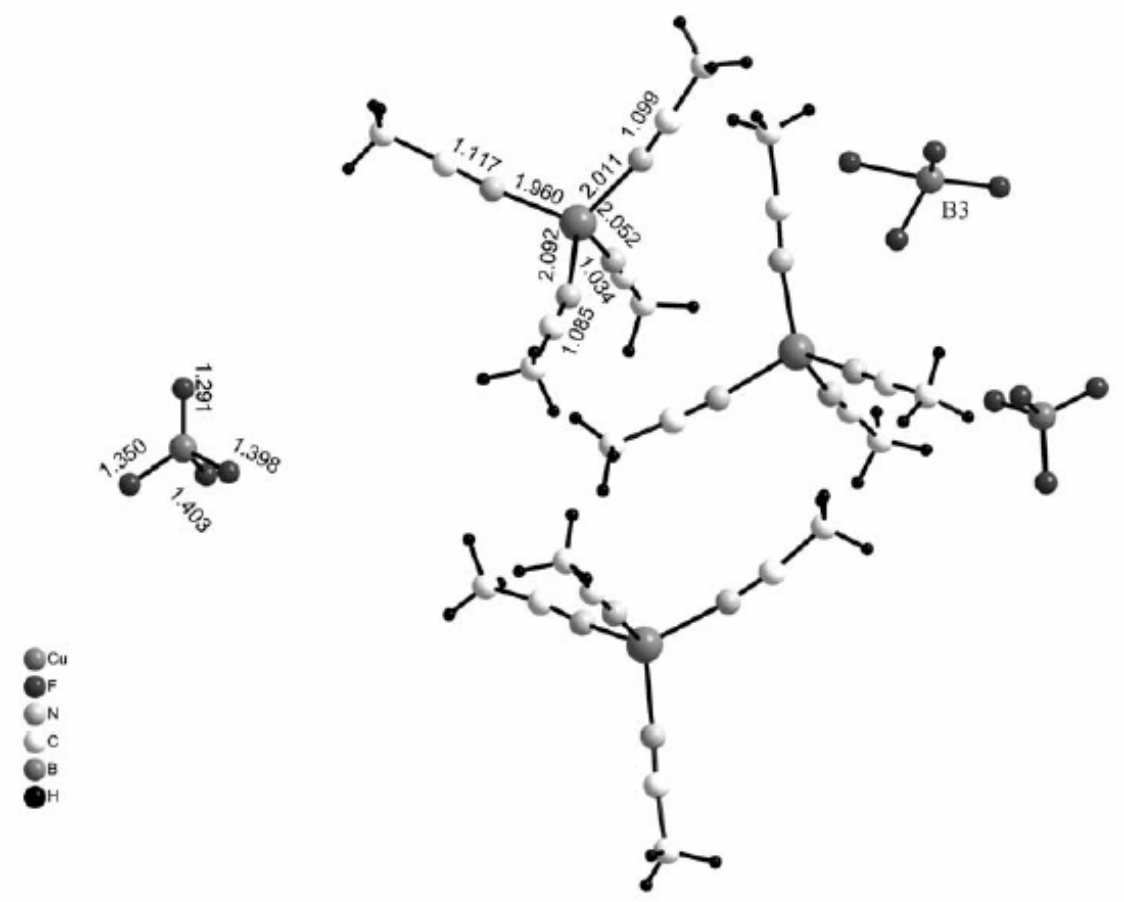

Fig. 3 Optimized 3D-structure of the crystalline $\left[\mathrm{Cu}\left(\mathrm{CH}_{3} \mathrm{CN}\right)_{4}\right]^{+} \mathrm{BF}_{4}^{-}$complex.

Table 1 Crystallographic data for $\left[\mathrm{Cu}\left(\mathrm{CH}_{3} \mathrm{CN}\right)_{4}\right] \mathrm{BF}_{4}$ and isostructural $\mathrm{CuClO}_{4} \cdot 4 \mathrm{CH}_{3} \mathrm{CN}$.

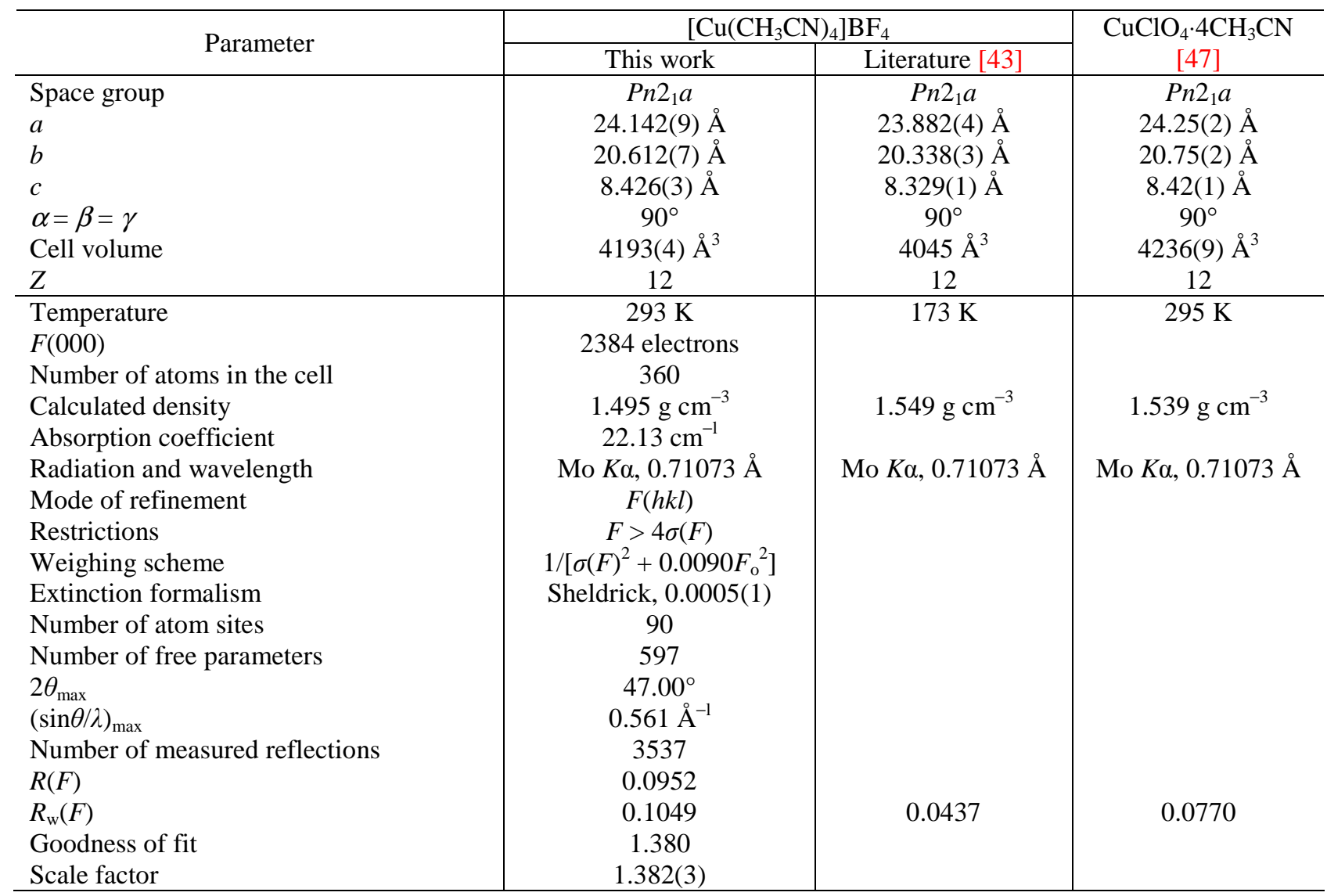


Because this reaction proceeds in acetonitrile, $\mathrm{CH}_{3} \mathrm{CN}$ molecules react with azophenyl copper, to form what can be regarded as a complex compound when its coordination sphere will be completed to 4 :

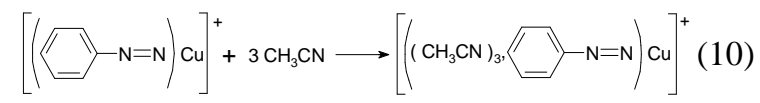

The formation of $\mathrm{Cu}(\mathrm{I})$ mixed complexes was observed by Parsons et al., who isolated and identified the $\left[\mathrm{Cu}_{3}(\text { dpphp })_{2}\left(\mathrm{CH}_{3} \mathrm{CN}\right)_{1.7}\left(\mathrm{CH}_{2} \mathrm{Cl}_{2}\right)_{0.3}\right] \mathrm{ClO}_{4}$ complex (where dpphp - 6-diphenylphosphino-2-hydroxypyridine) [48]. This complex is unstable and decomposes into crystalline $\left(\mathrm{Cu}\left(\mathrm{CH}_{3} \mathrm{NC}_{4} \mathrm{BF}_{4}\right)\right.$ and amorphous phases, the latter being a mixture of dimeric and oligomeric nitrogenated organic compounds. The mechanism of copper dissolution via an intermediate stage of formation of mixed azophenyl acetonitrile $\mathrm{Cu}(\mathrm{I})$ complexes correlates well with the experimental observation of partial DAS dediazotization $(70 \%)$ during the interaction with copper powder.

\section{Conclusions}

During copper dissolution-ionization in concentrated $(\geq 0.05 \mathrm{M})$ acetonitrile solutions of benzenediazonium tetrafluoroborate only $70 \%$ of the initial DAS had dediazotized. The remaining DAS had reduced according to an inner sphere mechanism where the products are azophenyl radicals, which can be explained by reactions of copper with both the initial diazonium salt and intermediates. The $\mathrm{Cu}-\mathrm{BDFB}$ interaction is accompanied by an intense gas $\left(\mathrm{N}_{2}\right)$ evolution and a rapid change of the initial light-yellow color of the solution to purple-red with different hues that are connected with the formation of an intermediate, which corresponds to an electronic absorption band with a maximum around $420 \mathrm{~nm}$. This intermediate is a complex of $\mathrm{Cu}(\mathrm{I})$, namely $\left[\mathrm{Cu}-\left(\mathrm{N}=\mathrm{N}-\mathrm{C}_{6} \mathrm{H}_{5}\right)\left(\mathrm{N} \equiv \mathrm{C}-\mathrm{CH}_{3}\right)_{3}\right]^{+} \mathrm{BF}_{4}^{-}$, where $\mathrm{Cu}$ is coordinated to three solvent molecules and forms a chemical bond with the azophenyl group. The complex decomposes slowly with the formation of a crystalline phase, wihch was identified as $\left[\mathrm{Cu}\left(\mathrm{N} \equiv \mathrm{C}-\mathrm{CH}_{3}\right)_{4}\right]^{+} \mathrm{BF}_{4}^{-}$, and an amorphous phase, which is a mixture of oligomers containing phenyl and azophenyl fragments.

\section{Acknowledgements}

The research described in this publication was made possible in part by Grant No. 0109U002074 of the Ministry of Education and Sciences of Ukraine. The authors also thank Prof. Maryan G. Mys'kiv from the Department of Inorganic chemistry, Ivan Franko National University of Lviv for help during the X-ray diffraction studies.

\section{References}

[1] J. Pinson, F. Podvorica, Chem. Soc. Rev. 34 (2005) 429-439.

[2] J.A. Harnisch, D.B. Gazda, J.W. Anderegg, M.D. Porter, Anal. Chem. 73 (2001) 3954-3959.

[3] R. Polsky, J.C. Harper, D.R. Wheeler, S.M. Brozik, Electroanalysis 20 (2008) 671-679.

[4] Y.L. Zhong, K.P. Loh, A. Midya, Z.K. Chen, Chem. Mater. 20 (2008) 3137-3144.

[5] M.A. Ratner, Mater. Today 5 (2002) 20-27.

[6] S.M. Dirk, D.W. Price, S. Chanteau, D.V. Kosynkin, J.M. Tour, Tetrahedron 57 (2001) 5109-5121.

[7] C. Galli, Chem. Rev. 88 (1988) 765-792.

[8] E.P. Koval'chuk, Z.E. Kozłowska, L. Józwiak, J. Błażejowski, Pol. J. Chem. 74 (2000) 67-78.

[9] R.M. Elofson, F.F. Gadallah, K.F. Schulz, J.K. Laidler, Can. J. Chem. 62 (1984) 17721774.

[10] O. Orange, C. Elfakir-Hamet, C. Caullet, J. Electrochem. Soc. 128 (1981) 1889-1894.

[11] E. Ahlberg, B. Helgée, V.D. Parker, Acta Chem. Scand. B 34 (1980) 181-186.

[12] A. Chaussé, M.M. Chehimi, N. Karsi, J. Pinson, F. Podvorica, C. Vautrin-Ul, Chem. Mater. 14 (2002) 392-400.

[13] P. Allongue, M. Delamar, B. Desbat, O. Fagebaume, R. Hitmi, J. Pinson, J.-M. Saveant, J. Am. Chem. Soc. 119 (1997) 201-207.

[14] Y.-C. Liu, R.L. McCreery, Anal. Chem. 69 (1997) 2091-2097.

[15] T.-C. Kuo, R.L. McCreery, G.M. Swainb, Electrochem. Solid-State Lett. 2 (1999) 288-290.

[16] C. Saby, B. Ortiz, G.Y. Champagne, D. Bélanger, Langmuir 13 (1997) 6805-6813.

[17] M. Toupin, D. Belanger, J. Phys. Chem. C 111 (2007) 5394-5401.

[18] G. Chamouland, D. Belanger, J. Phys. Chem. C 111 (2007) 7501-7507.

[19] U.S. Patent No. 6494946, 2002.

[20] H. Zollinger, Diazo Chemistry I, Verlagsgesellschaft GmbH, Weinheim, 1994, Vol. 273.

[21] A. Adenier, E. Cabet-Deliry, A. Chaussé, S. Griveau, F. Mercier, J. Pinson, C. Vautrin-Ul, Chem. Mater. 17 (2005) 491-501.

[22] A. Adenier, N. Barré, E. Cabet-Deliry, A. Chaussé, S. Griveau, F. Mercier, J. Pinson, C. Vautrin-Ul, Surface Sci. 600 (2006) 48014812.

[23] B.-T. Qian, Z.-Q. Shen, Langmuir 21 (2005) 9007-9009.

[24] E.P. Koval'chuk, O.V. Reshetnyak, V.Ya. Smetanets'kyj, Ukr. Khim. Zh. 71 (2005) 46-51.

[25] V. Smetanets'kyj, E. Koval'chuk, O. Reshetnyak, J. Błażejowski, R. Galyantyj, Visn. Lviv Univ., Ser. Khim. 46 (2005) 243-250. 
[26] E. Koval'chuk, Ya. Kovalyshyn, V. Smetanets'kyj, D. Korobiy, Visn. Lviv Univ., Ser. Khim. 43 (2003) 219-223.

[27] O. Reshetnyak, V. Smetanets'kyj, E. Koval'chuk, J. Błażejowski, M. Protsak, Visn. Lviv Univ., Ser. Khim. 47 (2006) 227-234.

[28] C. Galli, J. Chem. Soc. Perkin Trans. 211 (1981) 1459-1461.

[29] B.D. Grishchuk, P.M. Gorbovoi, N. I. Ganushchak, A.V. Dombrovskii, Russ. Chem. Rev. 63 (1994) 257-267.

[30] A.V. Dombrovskiy, V.M. Najdan, Organic Chemistry, Vyshcha shkola, Kyiv, 1992.

[31] L.G. Akselrud, P.Yu. Zavalii, Yu.N. Grin, V.K. Pecharski, B. Baumgartner, E. Wölfel, Mater. Sci. Forum 133-136 (1993) 335-340.

[32] T. Cohen, R.J. Lewarchik, J.Z. Tarino, J. Am. Chem. Soc. 96 (1974) 7753-7760.

[33] B.M. Mykhalichko, T. Glovjak, M.G. Mys'kiv, Russ. J. Inorg. Chem. 40 (1995) 757-762.

[34] B.M. Mykhalichko, M.G. Mys'kiv, E.A. Goreshnik, Russ. J. Coord. Chem. 25 (1999) 60-64.

[35] M. Shiotsuka, T. Tanamachi, T. Urakawa, M. Munakata, Y. Matsuda, J. Supramol. Chem. 2 (2002) 211-217.

[36] M. Harmata, S.K. Ghosh, C.L. Barnes, J. Supramol. Chem. 2 (2002) 349-351.

[37] M.M. Al-Ktaifani, P.B. Hitchcock, J.F. Nixon, J. Organomet. Chem. 665 (2003) 101-106.
[38] S. Frantz, J. Rall, I. Hartenbach, T. Schleid, S. Záliš, W. Kaim, Chem. Eur. J. 10 (2004) 149154.

[39] W. Szczepaniak, Instrumental methods in chemical analysis, PWN, Warszawa, 1997.

[40] K. Nakanishi, Infrared Absorption Spectroscopy-Practical (2nd ed.), Tokyo, 1964.

[41] N.L. Alpert, E.E. Keiser, H.A. Szymanski, Infrared spectroscopy. Theory and practice, PWN, Warszawa, 1974.

[42] E.P. Koval'chuk, Z.E. Kozlovs'ka, K. Jackowska, A. Roshal, A. Wróblewska, O.V. Reshetnyak, J. Błażejowski, Polish J. Chem. 78 (2004) 139-147.

[43] P.G. Jones, O. Crespo, Acta Crystallogr. C 54 (1998) 18-20.

[44] C-W. Shih, Y-Y. Wang, C.-C. Wan, J. Appl. Electrochem. 32 (2002) 987-992.

[45] C-W. Shih, Y-Y. Wang, C.-C. Wan, J. Appl. Electrochem. 33 (2003) 403-410.

[46] J. McCall, D. Bruce, S. Workman, C. Cole, M.M. Richter, Anal. Chem. 73 (2001) 46174620.

[47] I. Csoregh, P. Kirkegaard, N. Norrestam, Acta Crystallogr. B 31 (1975) 314-317.

[48] S. Parsons, Z. Pikramenou, G.A. Solan, R.E.P. Winpenny, J. Cluster Sci. 11 (2000), 227-232. 